\title{
Repair of the Injured Adult Hippocampus through Graft- Mediated Modulation of the Plasticity of the Dentate Gyrus in a Rat Model of Temporal Lobe Epilepsy
}

\author{
Ashok K. Shetty, Vandana Zaman, and Bharathi Hattiangady \\ Department of Surgery (Neurosurgery), Duke University Medical Center, Durham, North Carolina 27710, and Medical Research and Surgery Services, \\ Veterans Affairs Medical Center, Durham, North Carolina 27705
}

\begin{abstract}
Intracerebroventricular kainate administration in rat, a model of temporal lobe epilepsy (TLE), causes degeneration of the hippocampal CA3 pyramidal and dentate hilar neurons. This leads to a robust but aberrant sprouting of the granule cell axons (mossy fibers) into the dentate supragranular layer and the CA3 stratum oriens. Because this plasticity is linked to an increased seizure susceptibility in TLE, strategies that restrain the aberrant mossy fiber sprouting (MFS) are perceived to be important for preventing the TLE development after the hippocampal injury. We ascertained the efficacy of fetal hippocampal CA3 or CA1 cell grafting into the kainate-lesioned CA3 region of the adult rat hippocampus at early post-kainic acid injury for providing a lasting inhibition of the aberrant MFS. Analyses at 12 months after grafting revealed that host mossy fibers project vigorously into CA3 cell grafts but avoid CA1 cell grafts. Consequently, in animals receiving CA3 cell grafts, the extent of aberrant MFS was minimal, in comparison with the robust MFS observed in both "lesion-only" animals and animals receiving CA1 cell grafts. Analyses of the graft axon growth revealed strong graft efferent projections into the dentate supragranular layer with CA3 cell grafting but not with CA1 cell grafting. Thus, the formation of reciprocal circuitry between the dentate granule cells and the grafted CA3 pyramidal neurons is likely the basis of inhibition of the aberrant MFS by CA3 cell grafts. The results also underscore that grafting of cells capable of differentiating into CA3 pyramidal neurons is highly efficacious for a lasting inhibition of the abnormal mossy fiber circuitry development in the injured hippocampus.
\end{abstract}

Key words: brain repair; efferent graft projections; graft- host connectivity; hippocampal CA3 cells; kainic acid; mossy fiber sprouting; neural grafting; neural transplant integration

\section{Introduction}

Cell transplantation into the adult rat hippocampus after injury is an ideal prototype to study the prospective restorative effects of distinct cell grafts in conditions such as the temporal lobe epilepsy (TLE), stroke, and head injury (Shetty and Turner, 1996; Turner and Shetty, 2003). Intracerebroventricular kainic acid (KA) administration in rat, a model of TLE, causes degeneration of CA3 pyramidal neurons and dentate hilar cells, the target cells of granule cell axons (mossy fibers). This leads to the formation of aberrant hippocampal circuitry characterized by the mossy fiber sprouting (MFS) into the dentate supragranular layer (DSGL), akin to the change seen in the human TLE (Babb et al., 1991; Mathern et al., 1996). The mossy fibers also sprout into the CA3 stratum oriens in the injured hippocampus (Represa and BenAri, 1992). The sprouted mossy fibers in the dentate gyrus (DG) form new synapses on granule cell dendrites, which increase the excitatory connections between granule cells (Buckmaster et al.,

Received April 19, 2005; revised July 29, 2005; accepted July 31, 2005

This work was supported by National Institute of Neurological Disorders and Stroke Grant R01 NS 043507 (A.K.S.) and a grant from the Department of Veterans Affairs (Veterans Affairs Merit Review Award) (A.K.S.).

Correspondence should be addressed to Dr. Ashok K. Shetty, Division of Neurosurgery, Duke University Medical Center Box 3807, Duke University Medical Center, Durham, NC 27710. E-mail: ashok.shetty@duke.edu. D0I:10.1523/JNEUROSCI.1538-05.2005

Copyright $\odot 2005$ Society for Neuroscience $\quad$ 0270-6474/05/258391-11\$15.00/0
2002; Scharfman et al., 2003). The aberrant MFS after KA administration is likely a consequence of the degeneration of a large number of their postsynaptic target cells (CA3 pyramidal neurons) and afferent neurons (hilar mossy cells). Studies have shown that the degree of aberrant MFS correlates with both antidromically evoked burst firing and spontaneous seizures in kainate models of TLE (Mathern et al., 1993; Dudek et al., 1994; Wuarin and Dudek, 2001; Nadler, 2003).

Thus, the aberrant MFS in the DG is likely one of the major causes of increased seizure susceptibility in both TLE and animal models of TLE (Santhakumar et al., 2005). Therefore, treatment strategies that restrain the aberrant MFS after hippocampal injury have considerable significance for the development of apt therapy for TLE. Previously, we showed that mixed fetal hippocampal cell grafting into the lesioned CA3 region can suppress MFS into the DSGL (Shetty and Turner, 1997). Nevertheless, it is unknown whether the graft-mediated suppression of aberrant MFS depends on the presence of particular types of hippocampal cells within grafts and/or the establishment of precise graft-host connectivity. Additionally, the efficacy of grafts for providing an enduring suppression of the abnormal sprouting has not been studied. We hypothesize that a lasting graft-mediated suppression of the abnormal MFS in the injured hippocampus is critically dependent on the presence of CA3 pyramidal neurons in grafts. 
This is based on the premise that only CA3 pyramidal neurons can both attract host mossy fibers and significantly innervate the deafferented DSGL region leading to restoration of the disrupted circuitry and suppression of the aberrant MFS. We grafted embryonic day 19 (E19) hippocampal CA3 or CA1 cells into the KA-lesioned CA3 region of the adult hippocampus at 4 or $45 \mathrm{~d}$ after the intracerebroventricular KA administration, and analyzed the aberrant MFS into the DSGL and the CA3 stratum oriens at 12 months after grafting. For comparison, the extent of MFS was also evaluated from "lesion-only" animals. Furthermore, specific graft axon growth into the deafferented zones of the injured hippocampus was determined using grafting of E15 mouse hippocampal cells into the KA-lesioned rat hippocampus and M6 immunostaining.

\section{Materials and Methods}

The sequence of various experiments performed in this study is illustrated in the supplemental figure (available at www.jneurosci.org as supplemental material). These include kainic acid lesions of host animals, dissection and dissociation of fetal hippocampal CA3 and CA1 tissues from donor fetuses, transplantation, perfusions, Timm's histochemical staining and analyses of the aberrant MFS, cross-species grafting, immunostaining of the grafts for the mouse-specific antigen M6, and mapping of graft axonal projections.

Kainic acid lesions. A unilateral intracerebroventricular KA administration was performed on adult male Fischer 344 rats (4 months old; Harlan Sprague Dawley, Indianapolis, IN), using methods detailed previously (Shetty and Turner, 1995a,b, 1997, 2000). These protocols have been approved by the Duke University Institutional Animal Care and Use Committee and the Animal Studies Subcommittee of the Durham Veterans Affairs Medical Center. In brief, rats were anesthetized with a mixture solution containing ketamine $(50 \mathrm{mg} / \mathrm{ml})$, xylazine $(6 \mathrm{mg} / \mathrm{ml})$, and acepromazine $(0.5 \mathrm{mg} / \mathrm{ml})$ at a dose of $1.25 \mathrm{ml} / \mathrm{kg}$ body weight. After this, each rat was fixed into a stereotaxic apparatus, the incisor bars were set at $3.7 \mathrm{~mm}$ below the interaural line, and the dorsal surface of the skull was exposed. A burr hole was drilled in the skull using the following stereotaxic coordinates: anteroposterior (AP), $3.7 \mathrm{~mm}$ caudal to bregma; lateral (L), $4.1 \mathrm{~mm}$ right lateral to the midline. A $10 \mu \mathrm{l}$ Hamilton syringe fitted with a 25-gauge needle and filled with KA solution in saline was placed over the burr hole and lowered $4.5 \mathrm{~mm}$ below the surface of the brain, and $1 \mu \mathrm{l}$ of KA $(0.5 \mu \mathrm{g})$ was injected at a rate of $0.2 \mu \mathrm{l} / \mathrm{min}$. The needle was left in place for 15 min before being retracted slowly.

Collection of hippocampal CA3 and CA1 tissues from E19 rat fetuses. Fetuses were removed from deeply anesthetized pregnant rats by cesarean section and collected in a Petri plate containing calcium and magnesium free HBSS (Sigma, St. Louis, MO) with $0.6 \%$ glucose, $10 \mathrm{~mm}$ HEPES, and $1 \%$ penicillin-streptomycin, and brains were dissected under an operating microscope. For dissection of CA3 and CA1 tissues, each cerebral hemisphere was separated from the brainstem and cut coronally into four slices of equal size, and slices containing hippocampal tissue were identified under a dissection microscope. The middle two slices from each hemisphere were consistently found to contain hippocampal tissues. From each of these pieces, the hippocampal tissue was unfolded, and subfields CA3 (the lateral-most part of the hippocampus with the choroid plexus) and CA1 (the medial part of the hippocampus adjoining the subiculum) were separated by sharp cuts using a scalpel blade and collected separately in fresh HBSS (Shetty and Turner, 2000; Zaman et al., 2000, 2001). The CAl tissue collected this way also contained the primordial DG (supplemental figure, available at www.jneurosci.org as supplemental material), because the tiny area of the primordial DG could not be separated by the above procedure.

Preparation of cell suspension from hippocampal CA3 and CA1 tissues. After dissection, the hippocampal CA3 and CA1 tissues were processed separately for dissociation and preparation of a single-cell suspension using mechanical trituration (supplemental figure, available at www. jneurosci.org as supplemental material). Using a fine polished Pasteur pipette, tissue pieces were triturated 30 times in $2 \mathrm{ml}$ of HBSS, and the resulting cell suspension was diluted with $10 \mathrm{ml}$ of fresh HBSS. The diluted cell suspension was then sieved through a steel mesh (pore size, $175 \mu \mathrm{m}$ ) and centrifuged at $800 \mathrm{rpm}$ for $8 \mathrm{~min}$, and the pellet was resuspended in HBSS. Cells were washed twice by resuspension in HBSS and centrifugation. The final pellet was resuspended in $30 \mu \mathrm{l}$ of HBSS, and viability was assessed using the trypan blue exclusion method. The density of cells was then adjusted to $1 \times 10^{5}$ viable cells/ $\mu l$ and stored on ice.

Transplantation. Kainic acid-treated rats (at 4 and $45 \mathrm{~d}$ after KA) were anesthetized and fixed into a stereotaxic apparatus. The plane of the incisor bar was set at $3.3 \pm 0.3 \mathrm{~mm}$ below the interaural line. The detailed transplantation procedure has been described previously (Shetty and Turner, 1995a, 1997). One microliter of the cell suspension, containing $\sim 100,000$ live cells, was injected into each of the following three locations in the hippocampus ipsilateral to the KA lesion: (1) AP, $3.0 \mathrm{~mm}$ posterior to bregma; L, $2.2 \mathrm{~mm}$ right lateral to midline; and ventral $(\mathrm{V}), 3.5 \mathrm{~mm}$ from the surface of brain; (2) AP, $3.8 \mathrm{~mm}$;, $3.0 \mathrm{~mm}$ right lateral; V, 3.5 $\mathrm{mm}$; and (3) AP, $4.6 \mathrm{~mm}$; $\mathrm{L}, 4.0 \mathrm{~mm}$; and V, $3.5 \mathrm{~mm}$. These locations were chosen to place the grafts close to the degenerated CA3 pyramidal cell layer.

Analysis of KA lesions and the extent of mossy fiber sprouting. The MFS was analyzed in intact control (naive) rats; KA-treated rats at 1.5, 4, and 12 months after KA (lesion-only rats); KA-treated rats receiving CA3 or CA1 cell grafts at $4 \mathrm{~d}$ after KA and killed at 12 months after grafting; and KA-treated rats receiving CA3 cell grafts at $45 \mathrm{~d}$ after KA and killed at 12 months after grafting. The control (naive) animals used in this study did not undergo sham intracerebroventricular KA injection surgery, because our previous study showed that sham intracerebroventricular KA injection surgery leads to no changes in hippocampal cytoarchitecture (Shetty and Turner, 1995b). Similarly, the lesion-only rats used in this study did not undergo sham-grafting surgery, because our pilot studies have shown that sham grafting surgery into the hippocampus of KA-treated rats does not prevent the development of aberrant MFS. All animals were deeply anesthetized with halothane and perfused transcardially with the modified fixation procedure for Timm's histochemical staining (Mitchell et al., 1993). Briefly, after a rinse in the physiological saline (150 ml; 5-8 $\mathrm{min}$ ), animals were perfused with $100 \mathrm{ml}$ of $1 \%$ sodium sulfide solution followed by $100 \mathrm{ml}$ of $4 \%$ paraformaldehyde and finally with an additional $50 \mathrm{ml}$ of $1 \%$ sodium sulfide. The brains were removed, postfixed in $4 \%$ paraformaldehyde for $3 \mathrm{~h}$ at $4^{\circ} \mathrm{C}$, and cryoprotected in $30 \%$ sucrose solution in phosphate buffer (PB). Twenty-micrometer-thick cryostat sections were cut coronally through the hippocampus and collected serially in PB. Every 12th section through the hippocampus was stained for Nissl. Nissl staining confirmed the completeness of the KA-induced lesion in lesion-only animals. However, in "lesioned and grafted" animals, Nissl staining showed both cell loss induced by the KA lesion and the location of the transplant in relation to the degenerated CA3 cell layer. In all KA-treated groups, only the animals that exhibited classic intracerebroventricular KA lesion were chosen for additional analyses. The classic intracerebroventricular KA lesion is characterized by significant loss of dentate hilar neurons throughout the hippocampus, complete loss of CA3 pyramidal neurons except in a small region of CA3a cell layer adjoining the CA2, and partial loss of CA1 pyramidal neurons in the posterior one-half of the hippocampus. Furthermore, throughout the hippocampus, animals with classic intracerebroventricular KA lesion do not exhibit loss of neurons in the granule cell layer.

In all intact control and lesion-only animals, every sixth section through the hippocampus at levels corresponding to $3.0-5.0 \mathrm{~mm}$ posterior to bregma (Paxinos and Watson, 1998) was selected and processed for Timm's histochemical staining to demonstrate mossy fibers in the hippocampus. This protocol ensured that selected sections were independent from one another to clearly avoid analysis of MFS from adjacent sections and hence replication of the findings of the first section. All grafted brains had distinct transplants; however, only the brains with intrahippocampal transplants were selected for additional analysis; $>80 \%$ of grafted brains reached this threshold. Every sixth section through the grafted region from these brains (at levels corresponding to $3.0-5.0 \mathrm{~mm}$ posterior to bregma) was processed for Timm's histochemical staining to demonstrate mossy fibers in the grafted hippocampus. In lesioned, grafted animals, it was also ensured that the selected sections 
contained a transplant in the close vicinity of the degenerated CA3 cell layer (i.e., predominantly in the CA3 subfield, or partly in the CA3 subfield and partly below the degenerated CA3 layer in the lateral ventricle). Coronal sections through the hippocampus at levels specified above were chosen, because the injected transplants were clearly located at these levels. Timm's histochemical staining was performed as detailed previously (Danscher, 1981). Briefly, sections were mounted on gelatincoated slides and air-dried. Then, the slides containing sections were rinsed in distilled water, placed in jars, covered with the developer for Timm's staining, and immediately placed in the water bath at $26^{\circ} \mathrm{C}$ for $150 \mathrm{~min}$. The jars were placed in a dark room to reduce the autocatalytic staining of the solution. After development, the sections were rinsed several times in distilled water, processed for light Nissl staining with cresyl violet, dehydrated, cleared, and coverslipped with Permount.

Morphometric analysis of mossy fiber sprouting into the dentate supragranular layer. Kainic acid lesion-induced MFS into the DSGL was compared between different groups of animals using two separate and independent quantitative methods. These included measurement of the average width of the MFS and the density of Timm's granules in the dentate inner molecular layer. The degree of sprouting was measured in all regions of the DG (suprapyramidal and infrapyramidal blades and the crest) with both quantitative methods. In each animal, four sections through the hippocampus (separated by $240 \mu \mathrm{m}$ distance) at levels mentioned previously were measured. Measurements in sections from various groups were performed in a blinded manner using experimental codes. The average width of the DSGL sprouting was measured using Scion Image (Scion, Frederick, MD) based on NIH Image for Macintosh. The length and area of the DSGL MFS in all three regions of the DG were marked in every section, and the average width of DSGL sprouting for each relevant region of the DG was calculated for every animal before determining the group means and SEs. The densitometric analysis consisted of measuring the optical density of the inner and outer molecular layer in these representative sections (four per animal) using a compound microscope under a $40 \times$ objective. Using a digital camera (Optronics, Goleta, CA), representative areas of the suprapyramidal and infrapyramidal blades and the dentate crest were imaged, digitized, and stored. Then, the Scion Image was used to draw a region of interest in both the DSGL region (inner molecular layer) and the middle and outer molecular layers on the same image. The dimensions of these regions were $70 \times 70 \mu \mathrm{m}$, with an area of $\sim 4.9 \times 10^{3} \mu \mathrm{m}^{2}$ for each region. The background of the inner molecular layer was very similar to that of the middle and outer molecular layers, if no supragranular sprouting was present. Thus, it was assumed that the more distal molecular layer was a control region for the inner molecular layer, and the difference in pixel value between the inner and outer molecular layers was determined for the corresponding regions of interest. This measurement provided a highly objective and specific measure of the density of Timm's granule staining in the DSGL, corrected for the background control density expected in the molecular layer and other nonspecific differences between sections, such as the background staining level. These values were expressed in final form as a difference (inner molecular layer minus the outer molecular layer value), which ranged between 0 (no sprouting) and 255 (extremely dense Timm's staining representative of sprouting).

The quantification was performed in the following groups of animals: (1) intact control (naive) animals $(n=4)$; (2) animals treated with intracerebroventricular KA alone (lesion-only rats), at 4 and 12 months after administration ( $n=4 /$ time point); (3) intracerebroventricularly KA-treated animals receiving CA3 or CA1 cell grafts at $4 \mathrm{~d}$ after KA and killed at 12 months after grafting ( $n=6 /$ transplant group); and (4) intracerebroventricularly KA-treated animals receiving CA3 cell grafts at $45 \mathrm{~d}$ after KA and killed at 12 months after grafting $(n=4)$. All animals measured in the intracerebroventricularly KA-lesioned groups have satisfied the criteria of classic intracerebroventricular KA lesion described previously. The mean value for each of the three regions of the DG (suprapyramidal and infrapyramidal blades and the crest) was calculated separately for each animal by using data from four sections before the means and SEs were determined for the total number of animals included per group. Mean values between different groups of animals were separately compared for every region of the DG. Statistical comparisons in- volved ANOVA with Student-Newman-Keuls multiple comparisons test. To determine the mean sprouting values for the entire DG in terms of both width of the sprouted area and the density of sprouted terminals in the DSGL, individual values measured from suprapyramidal and infrapyramidal blades and the crest of the DG were averaged in every animal, and then, means and SEs were calculated in every group for the total number of animals included for measurement. The mean values for both width of sprouted area and the density of sprouted terminals were compared statistically between different groups of animals.

Analysis of the graft volume. For estimation of the total volume of each graft, we used the Cavalieri method. First, the entire area of the transplant in every 12th Nissl stained section was measured using the Neurolucida (MicroBrightField, Williston, VT). Then, the graft areas obtained from all of the measured sections were summed, and the total area for each graft was multiplied by the distance $d$. The distance $d$ was estimated through multiplication of the section thickness by 12 . The number 12 was used, because the transplant areas were measured in every 12th section.

Analyses of graft axon growth. The pattern of axon growth from CA3 and CAl cell grafts was analyzed using the cross-species transplantation protocol. This involved transplantation of E15 mouse hippocampal cells (CA3 or CA1 cells) into the lesioned CA3 region of the adult rat hippocampus at $4 \mathrm{~d}$ after lesion and analysis of the graft axon growth at $30 \mathrm{~d}$ after grafting using immunostaining for a mouse-specific antigen, M6. The dissection, cell suspension preparation, and grafting of mouse CA3 and CA1 cells were performed as described previously for rat hippocampal cells. Grafted rats were immunosuppressed using daily subcutaneous injections of the cyclosporine A ( $12 \mathrm{mg} / \mathrm{kg}$ body weight). For M6 immunostaining, rats were perfused with $4 \%$ paraformaldehyde, and tissues processed for cryostat sectioning using the standard procedure. Thirtymicrometer-thick horizontal sections through the hippocampus were cut and collected serially in PB. Sections containing transplants were processed for M6 immunostaining (Shetty and Turner, 1999). The M6 antibody (from Hybridoma Bank, Iowa City, IA; originally developed by Dr. Carl Lagenaur, University of Pittsburgh, Pittsburgh, PA) used in this study has been well characterized in cross-species grafting studies (Davies et al., 1994). Although M6 cannot differentiate subtypes of cells from the mouse, it has been found to be very useful in differentiating all mouse cell types in the presence of rat tissue substrates. In our hands, M6 immunohistochemistry has consistently resulted in predominant staining of axons of mouse tissue with some staining of the soma of mouse neural cells. Thus, the M6 immunostaining of mouse neural cells transplanted to rat tissues is useful to specifically identify mouse axons distributed within rat tissues. Sections were washed thoroughly in $0.1 \mathrm{M}$ PBS, blocked with $1 \%$ dried milk in PBS for $30 \mathrm{~min}$, and incubated overnight at $4^{\circ} \mathrm{C}$ with $1: 30$ dilution of M6 antibody in a solution containing PBS, $1 \%$ dried milk, and $0.1 \%$ Triton X-100. Sections were washed in PBS and incubated for $2 \mathrm{~h}$ in 1:100 anti-rat IgG (Sternberger Monoclonals, Lutherville, MD), washed three times in PBS, and incubated for $2 \mathrm{~h}$ in 1:400 rat clono-PAP (Sternberger Monoclonals). After three washes in PBS, the peroxidase reaction was developed using 3,3-diaminobenzidine (DAB) as chromogen (DAB kit; Vector Laboratories, Burlingame, CA). The immunostained sections were mounted on subbed slides, air dried, dehydrated, cleared, coverslipped, and examined under a Nikon (Melville, NY) microscope. The distribution and pattern of M6-positive axons emanating from mouse hippocampal CA 3 and CA1 cell grafts in the host hippocampal and septal regions were identified, analyzed, and photographed.

Furthermore, the differences in axon growth between CA3 and CA1 cell grafts transplanted into the injured CA3 region of the adult hippocampus were quantified. For this, the overall graft axon growth from CA3 and CA1 cell grafts into the deafferented zones of the injured hippocampus (the CAl strata oriens and radiatum, the dentate hilus, the dentate inner molecular layer) and the septum was measured using M6immunostained sections. Three representative sections containing graft axons were used for this quantification in each of the two transplant groups ( $n=5$ /group). Measurements in sections from the two groups were performed in a blinded manner using experimental codes. Quantification was performed using Scion Image. The areas occupied by the M6-immunoreactive structures per unit area of the above regions were 
determined. For each of the above regions, the microscopic image of the M6 immunoreactivity was transferred to the computer screen by focusing the appropriate area of the immunostained section with a Nikon E600 microscope equipped with a digital video camera (Optronics) connected to an IBM computer. Images were digitized using the $20 \times$ lens. The same intensity of light in the microscope and the same parameters in the digital camera were used to digitize all images in gray scale from different animals. The images were captured from the middle one-third of the upper blade of the DG for dentate inner molecular layer measurements, the middle one-third of the CA1 subfield for CA1 strata oriens and radiatum measurements. For dentate hilus measurements, the entire dentate hilus was used. All images were saved as BMP files for subsequent quantitative analyses using the Scion Image.

For measurements in each image, the boundaries of the region of interest were marked, and the total area of the marked region was measured. After this, the binary image of the M6-immunoreactive axons in the marked area was created by selecting a threshold value that keeps all immunoreactive elements but no background. The final binary image was cross-checked with the original gray scale image by alternating the two images on the computer screen. The area occupied by the M6immunoreactive structures in the binary image was then measured by selecting the "analyze particles" command of the Scion Image program. This way, the area of individual particles (i.e., the M6-immunoreactive axons) in the selected field was measured, and the sum area of all particles was stored for additional calculations and statistical analyses. Because spatial calibration of the image was performed in micrometers using the "set scale" function of the program before measurements, the results from area measurements were obtained in square micrometers. The value for each region was calculated separately by using data from three sections before the means and SEs were determined for the total number of samples $(n=5)$ included per group. The values were compared between the two groups of animals (i.e., the animals receiving CA3 or CA1 cell transplants) using an unpaired, two-tailed Student's $t$ test.

\section{Results \\ Hippocampal cytoarchitecture and aberrant mossy fiber sprouting after intracerebroventricular KA administration}

Evaluation of the Nissl-stained sections at different time points after the intracerebroventricular KA administration confirmed degeneration of the dentate hilar neurons and CA3 pyramidal neurons in the hippocampus ipsilateral to the intracerebroventricular KA administration. Significant loss of dentate hilar neurons was evident throughout the septotemporal axis of the hippocampus. The CA3 pyramidal cell layer showed widespread neurodegeneration throughout the hippocampus; however, some CA3 pyramidal neurons persisted at all anteroposterior levels in a small area of CA3a subregion adjacent to the CA2 cell layer. The granule cell layer was completely spared throughout the hippocampus. The CA1 pyramidal cell layer, however, was spared in the anterior one-half of the hippocampus but showed partial neurodegeneration in the posterior one-half of the hippocampus. The above pattern of neurodegeneration (referred to as "classic intracerebroventricular KA lesion" in Materials and Methods) is consistent with our multiple previous reports (Shetty and Turner, 1995a,b, 1997, 2000; Shetty et al., 2003).

Analyses of the dentate mossy fibers using the Timm's histochemical staining revealed an aberrant MFS in the DG of the hippocampus ipsilateral to the KA administration, which is in contrast to the intact hippocampus of control animals in which no such sprouting was present (Fig. $1 A 1, A 2$ ). At 1.5 months after KA, mossy fiber terminals could be observed in the DSGL, particularly in the ends of upper and lower blades of the granule cell layer (data not shown). At 4 months after KA, a dense broad band of sprouted mossy fibers could be seen in the DSGL (data not shown). The sprouting at this time point was uniform throughout the DG. The extent of MFS at 12 months after KA (Fig.
1B1-B4) was highly similar to the degree of sprouting observed at 4 months after KA as described in our previous study (Shetty et al., 2003). Thus, the aberrant dentate mossy fiber spouting after KA-induced hippocampal injury appears to reach saturation at 4 months after injury. However, this may be attributable to limitations of the Timm's histochemical staining to detect the increase in sprouted mossy fiber terminals between 4 and 12 months after injury.

Examination of the mossy fibers in the CA3 region of the KA-lesioned hippocampus revealed no sprouting of mossy fibers into the CA3 stratum oriens in areas where complete loss of CA3 pyramidal neurons were evident (i.e., in CA3c, CA3b, and most of CA3a cell layers). However, in a small segment of the CA3a cell layer (adjoining the CA2 cell layer) where CA3 pyramidal neurons persist after KA-induced injury, mossy fibers sprouted robustly into the CA3 stratum oriens (Fig. 2B1). Thus, the aberrant sprouting of mossy fibers into the CA3 stratum oriens in the KA-lesioned hippocampus occurs only in areas where CA3 pyramidal neurons persist. The sprouting of mossy fibers into the CA3 stratum oriens seen here is consistent with the observations in kindling models of epilepsy in which CA3 pyramidal neurons mostly persist after the development of kindling-related epilepsy, and the sprouted mossy fibers make new synapses on the basilar dendrites of the CA3 pyramidal neurons (Sutula et al., 1988; Cavazos et al., 1991; Represa and Ben-Ari, 1992; Represa et al., 1993).

\section{Location and morphology of transplants, and hippocampal cytoarchitecture, in grafted animals}

Examination of the KA-lesioned hippocampus of grafted animals at 12 months after grafting revealed surviving CA3 and CA1 cell grafts. Because E19 hippocampal cells do not exhibit migration after grafting, the graft location could be easily identified in all animals (Fig. 1C1,D1). The location and size of transplants in different groups are described in Table 1. Animals chosen for analyses in all groups had transplants located either predominantly in the CA3 subfield, or partly in the CA3 subfield and partly below the degenerated CA3 cell layer in the lateral ventricle (Table 1). Because the animals exhibiting classic intracerebroventricular KA lesion were chosen for all analyses (for details, see Materials and Methods), the overall host hippocampal lesion was similar in animals belonging to different transplant groups. Nissl staining demonstrated a large number of surviving neurons within all CA3 cell transplants, suggesting an excellent long-term survival of the grafted CA3 pyramidal neurons in the injured hippocampus, which is consistent with our previous quantitative studies on the survival of grafted cells in this model of TLE (Shetty and Turner, 2000; Zaman et al., 2000; Zaman and Shetty, 2001). Larger CA3 pyramidal neurons within CA3 cell grafts were mostly organized in clusters (Fig. 1C6,E6). The CA1 cell grafts also exhibited a large number of surviving neurons; however, the neurons were clearly smaller and were not arranged in clusters (Fig. 1D6).

The types of neurons encountered within CA 3 and CA1 cell transplants have been characterized previously and described in our previous reports (Shetty et al., 2000; Zaman et al., 2000). These results have mainly shown the following. First, the morphology (including size) of neurons encountered within CA3 and CA1 cell transplants is comparable with hippocampal CA3 and CA1 pyramidal neurons developed in situ (Zaman et al., 2000), respectively. Second, a large number of neurons within CA3 cell grafts express the CA3 pyramidal cell-specific markers, such as the nonphosphorylated neurofilament proteins; but neurons 


\title{
Mossy Fiber Sprouting into the Dentate Supragranular Layer
}

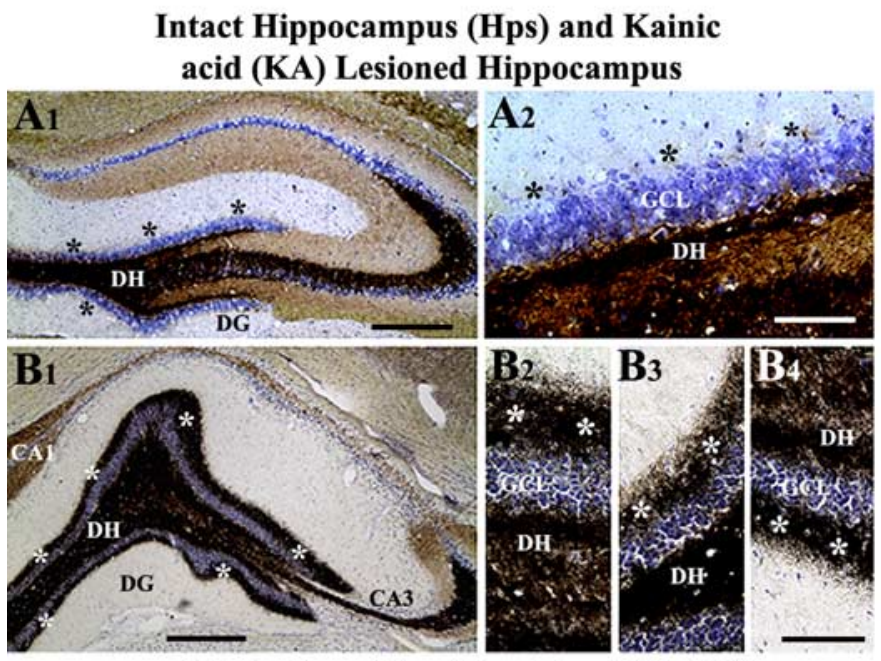

\author{
KA-Lesioned Hps Receiving CA3 Cell \\ Grafts at 4 Days Post-injury
}

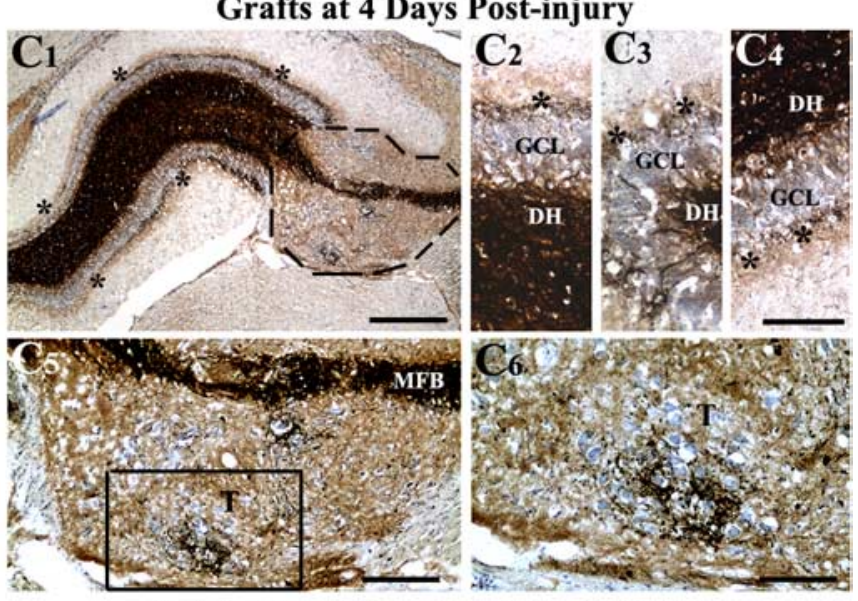

KA-Lesioned Hps Receiving CA1 Cell Grafts at 4 Days Post-injury
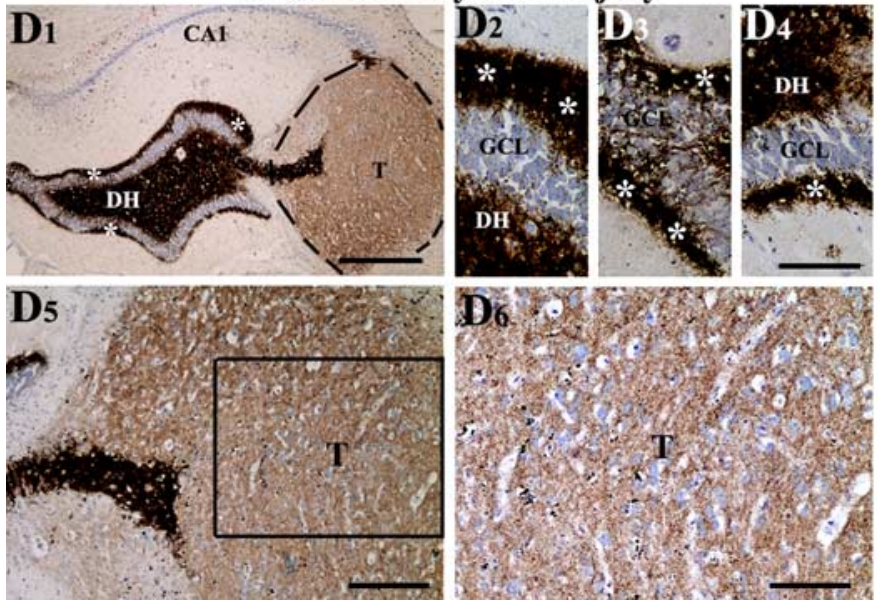

KA-Lesioned Hps Receiving CA3 Cell Grafts at 45 Days Post-injury

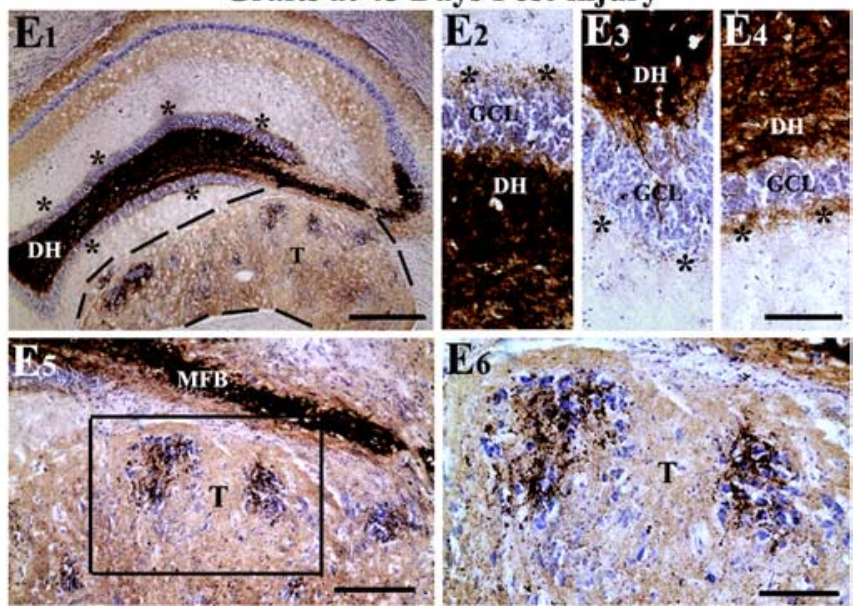

Figure 1. Extent of the mossy fiber sprouting in the dentate gyrus of control, lesion-only, and lesioned, grafted animals. $\boldsymbol{A} 1$, An example of the intact control hippocampus. $\mathbf{A} 2$ is an enlarged view of the upper blade of the dentate gyrus from $\boldsymbol{A} 1$ and demonstrates the absence of aberrant mossy fiber sprouting in the DSGL (black asterisks). $\boldsymbol{B} 1$, An example of the lesion-only hippocampus at 12 months after injury. $\boldsymbol{B 2}-\boldsymbol{B} 4$ are regions of the upper blade, the crest, and the lower blade of the dentate gyrus from $\boldsymbol{B} \mathbf{1}$ and demonstrate very robust aberrant mossy fiber sprouting into the DSGL (white asterisks). C1, An example of the lesioned hippocampus receiving CA3 cell grafts at $4 \mathrm{~d}$ after injury and analyzed at 1 year after grafting. The transplant (boundaries depicted by interrupted lines) is located in the CA3 region. (2-C4 are regions from the upper blade, the crest, and the lower blade of the dentate gyrus from C1 and show minimal aberrant mossy fiber sprouting into the DSGL (black asterisks). C5 illustrates the innervation of the transplant by host mossy fibers. C6 is an enlarged view of the boxed region of the transplant in C5 showing clusters of CA3 pyramidal neurons surrounded by mossy fiber terminals. D1, An example of the lesioned hippocampus receiving CA1 cell grafts at $4 \mathrm{~d}$ after injury and analyzed at 1 year after grafting. The graft (boundaries depicted by interrupted lines) is located in the CA3 region. D2-D4 are regions from the upper blade, the crest, and the lower blade of the dentate gyrus from D1 and show robust mossy fiber sprouting into the DSGL (white asterisks). D5 and D6 (enlarged view of the boxed region in D5) illustrate the absence of mossy fibers in regions of the CA1 transplant. E1, An example of the lesioned hippocampus receiving CA3 cell grafts at $45 \mathrm{~d}$ after injury and analyzed at 1 year after grafting. The graft (the boundaries depicted by interrupted lines) is located just below the CA3 region. E2-E4 are regions from the upper blade, the crest, and the lower blade of the dentate gyrus from $\boldsymbol{E} 1$ and demonstrate minimal aberrant mossy fiber sprouting into the DSGL (black asterisks). E5 shows the innervation of graft areas by host mossy fibers. $E 6$ is an enlarged view of the boxed region in $\mathbf{E 5}$ showing clusters of $(A 3$ pyramidal neurons surrounded by dense mossy fiber terminals. DH, Dentate hilus; GCL, granule cell layer; MFB, mossy fiber bundle; T, transplant. Scale bars: A1, B1, C1, D1, E1, $500 \mu \mathrm{m}$; $A 2$, (in B4) B2-B4, (in C4) C2-C4, C6, (in D4) D2-D4, D6, (in E4) E2-E4, E6, 100 $\mu \mathrm{m} ; C 5, D 5, E 5,200 \mu \mathrm{m}$.

within CA1 cell grafts do not express these proteins (Zaman et al., 2000). Third, neurons within CA3 cell grafts send efferent projections into both contralateral hippocampus (commissural connections) and the septum. However, neurons within the CA1 cell grafts send axonal projections into the septum but do not send projections into the contralateral hippocampus (Shetty et al., 2000). This pattern of distant efferent graft projections is consistent with the efferent pathways observed for the CA3 and CA1 pyramidal neurons developed in situ. Thus, several lines of evidence support that the CA3 and CA1 cell transplants contain a large number of CA3 and CA1 pyramidal neurons, respectively.
To determine whether the placement of transplants into the KAlesioned hippocampus results in a mass lesion, we examined the host CA3 tissue surrounding the transplant in both CA3 and CA1 graft groups. The host $\mathrm{CA} 3$ tissue surrounding the transplant did not display lesions in any of the transplant groups but contained uniformly distributed glial cells. Furthermore, the transplanthost interface did not demonstrate gliosis in both transplant groups. Thus, the transplantation of fetal cells (as single-cell suspension) into the KA-lesioned young adult hippocampus does not exacerbate injury. Furthermore, the transplanted cells engraft well into the degenerated CA3 cell layer and the adjoining regions 


\section{Mossy Fiber Sprouting into the CA3 Stratum Oriens}

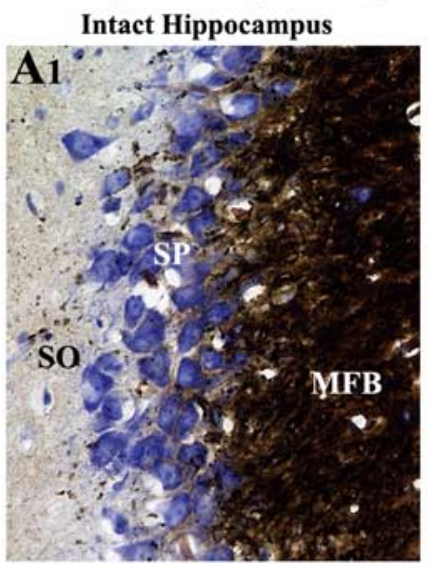

\section{KA-Lesioned Hippocampus}

Receiving CA3 Cell Grafts

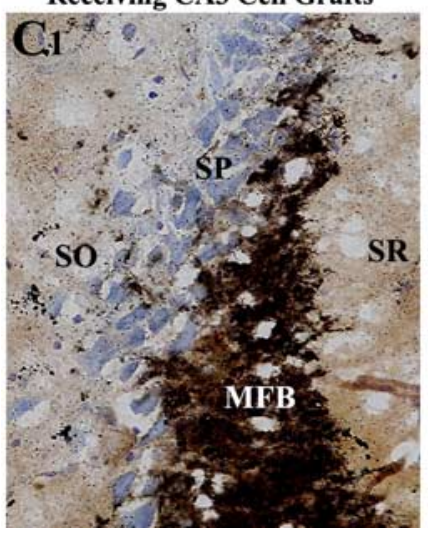

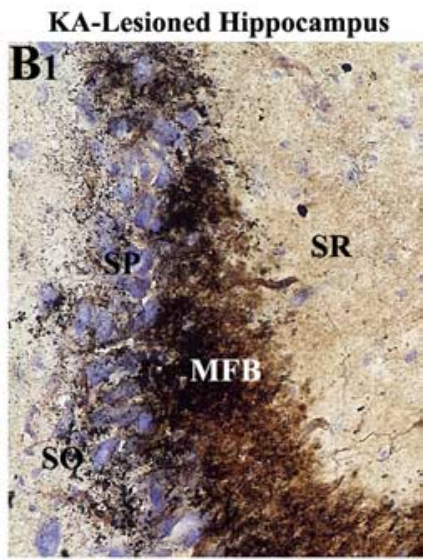

KA-Lesioned Hippocampus

Receiving CA1 Cell Grafts

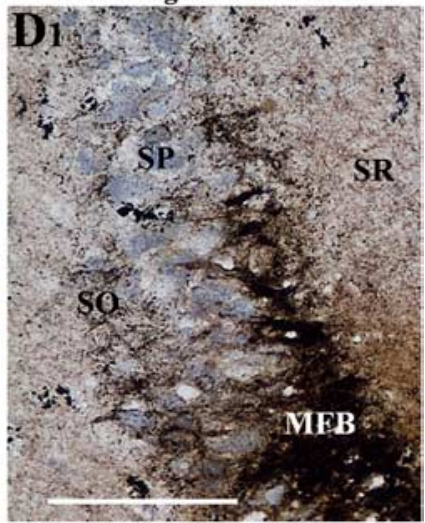

Figure 2. Extent of the mossy fiber sprouting into the stratum oriens of CA3a subregion in lesion-only and lesioned, grafted animals. A1, An example from the intact control hippocampus. The mossy fiber terminals are sparsely distributed in the stratum oriens $\left(S_{0}\right)$ and stratum pyramidale (SP) under intact conditions. B1, An example from the lesion-only hippocampus. A robust sprouting of mossy fiber terminals is evident in both $\mathrm{SO}$ and SP. C1, An example from an injured hippocampus receiving fetal $\mathrm{CA} 3$ cell transplants. Note that the mossy fiber terminals are sparse in both $\mathrm{SO}$ and SP, akin to that in the intact hippocampus (A1). D1, An example from an injured hippocampus receiving fetal CA1 cell transplants. A robust sprouting of mossy fiber terminals is obvious in both $\mathrm{SO}$ and SP, similar to the condition observed in the lesion-only hippocampus (B1). MFB, Mossy fiber bundle; SR, stratum radiatum. Scale bar: (in D1) A1-D1, $100 \mu \mathrm{m}$.

such as the CA3 stratum radiatum and the lateral ventricle below the degenerated CA3 cell layer.

\section{Effects of hippocampal CA3 and CA1 cell grafting on the aberrant mossy fiber sprouting}

In hippocampus receiving fetal hippocampal CA3 cell grafts at $4 \mathrm{~d}$ after the KA-induced injury and analyzed at 12 months after grafting, there was a clear reduction in both width and density of the MFS into the DSGL in all regions of the DG (Fig. 1C1-C4), in comparison with the age-matched lesion-only hippocampus

(Fig. 1B1-B4). Sprouts of host mossy fibers from the principal mossy fiber bundle clearly invaded CA3 cell grafts and densely innervated the clusters of CA3 pyramidal neurons (Fig. $1 C 1, C 5, C 6)$. In hippocampus receiving fetal hippocampal CA1 cell grafts at $4 \mathrm{~d}$ after injury and analyzed at 12 months after grafting (Fig. 1D1-D4), both width and density of MFS into the DSGL appeared comparable with lesion-only hippocampus (Fig. 1B1-B4). Furthermore, in these animals, host mossy fibers from the principal mossy fiber bundle did not invade CA1 cell grafts (Fig. 1D1,D5,D6). This was conspicuous even in animals in which grafts were placed just next to the principal mossy fiber bundle (Fig. 1D1). In hippocampus receiving fetal CA3 cell grafts at $45 \mathrm{~d}$ after KA (i.e., when the sprouts of mossy fibers have just began to grow into the DSGL) and analyzed at 12 months after grafting, there was a conspicuous reduction in both width and density of sprouting into the DSGL at all regions of the DG (Fig. $1 E 1-E 4)$, in comparison with the age-matched lesion-only hippocampus (Fig. 1 B1-B4). Similar to grafts placed at $4 \mathrm{~d}$ after KA, grafts placed at $45 \mathrm{~d}$ after KA attracted host mossy fibers. A dense innervation of the clusters of CA3 pyramidal neurons by host mossy fibers could be seen throughout the transplant (Fig. 1 E5,E6).

Because mossy fibers in lesion-only hippocampus exhibit abnormal sprouting into the stratum oriens of CA3a subregion (a subregion where some CA3 pyramidal neurons persist after KAinduced injury) (Fig. 2 B1), we examined the effects of CA3 and CA1 cell grafting on this sprouting too. In the lesioned hippocampus receiving CA3 cell grafts, there was a clear reduction in the density of the MFS in the stratum oriens of CA3a (Fig. 2C1). In contrast, in the lesioned hippocampus receiving CA1 cell grafts (Fig. 2D1), the density of sprouting in the CA3a stratum oriens appeared similar to that observed in lesion-only hippocampus (Fig. 2 B1). Thus, fetal hippocampal CA3 cell grafting into the injured hippocampus suppresses the formation of aberrant MFS not only in the DG but also in the CA3 subfield.

\section{Changes in the width and density of aberrant dentate mossy fiber sprouting with grafting}

Quantification of the width and density of the aberrant MFS in different groups clearly revealed that, in the injured hippocampus receiving CA3 cell grafts at 4 or $45 \mathrm{~d}$ after KA, the extent of the aberrant MFS was dramatically reduced throughout the DG, in comparison with lesion-only hippocampus (Fig. 3). The overall reductions in the width of sprouted area varied from 73 to $75 \%$ in the upper blade, 64 to $78 \%$ in the crest, $75 \%$ in the lower blade, and 72 to $75 \%$ in the entire DG (Fig. $3 A$ ). The reductions in the density of sprouted terminals varied from 80 to $83 \%$ in the upper blade, 75 to $76 \%$ in the crest, 75 to $81 \%$ in the lower blade, and 77 to $80 \%$ in the entire DG (Fig. $3 B$ ). Furthermore, the overall density of sprouted terminals in the DSGL of animals receiving intrahippocampal CA3 cell grafts was similar to that of the intact control animals (Fig. 3B). Thus, CA3 cell grafting is highly efficacious for inhibiting the aberrant MFS when performed at early

Table 1. Location and size of transplants in different groups

\begin{tabular}{lll}
\hline Transplant groups & Location of transplants & Transplant volume $\left(\mathrm{mm}^{3}\right)^{a}\left(\mathrm{mean}^{ \pm} \pm \mathrm{SEM}\right)$ \\
\hline CA3 transplants placed at $4 \mathrm{~d}$ after KA administration $(n=6)$ & $50 \%$ of transplants in the CA3 region & $0.57 \pm 0.1$ \\
& $50 \%$ of transplants in the CA3 region and lateral ventricle & \\
& All transplants in the CA3 region and lateral ventricle & $0.51 \pm 0.05$ \\
CA3 transplants placed at $45 \mathrm{~d}$ after KA administration $(n=4)$ & $50 \%$ of transplants in the CA3 region & $0.48 \pm 0.03$ \\
CA1 transplants placed at $4 \mathrm{~d}$ after KA administration $(n=6)$ & $50 \%$ of transplants in the CA3 region and lateral ventricle & \\
\hline
\end{tabular}



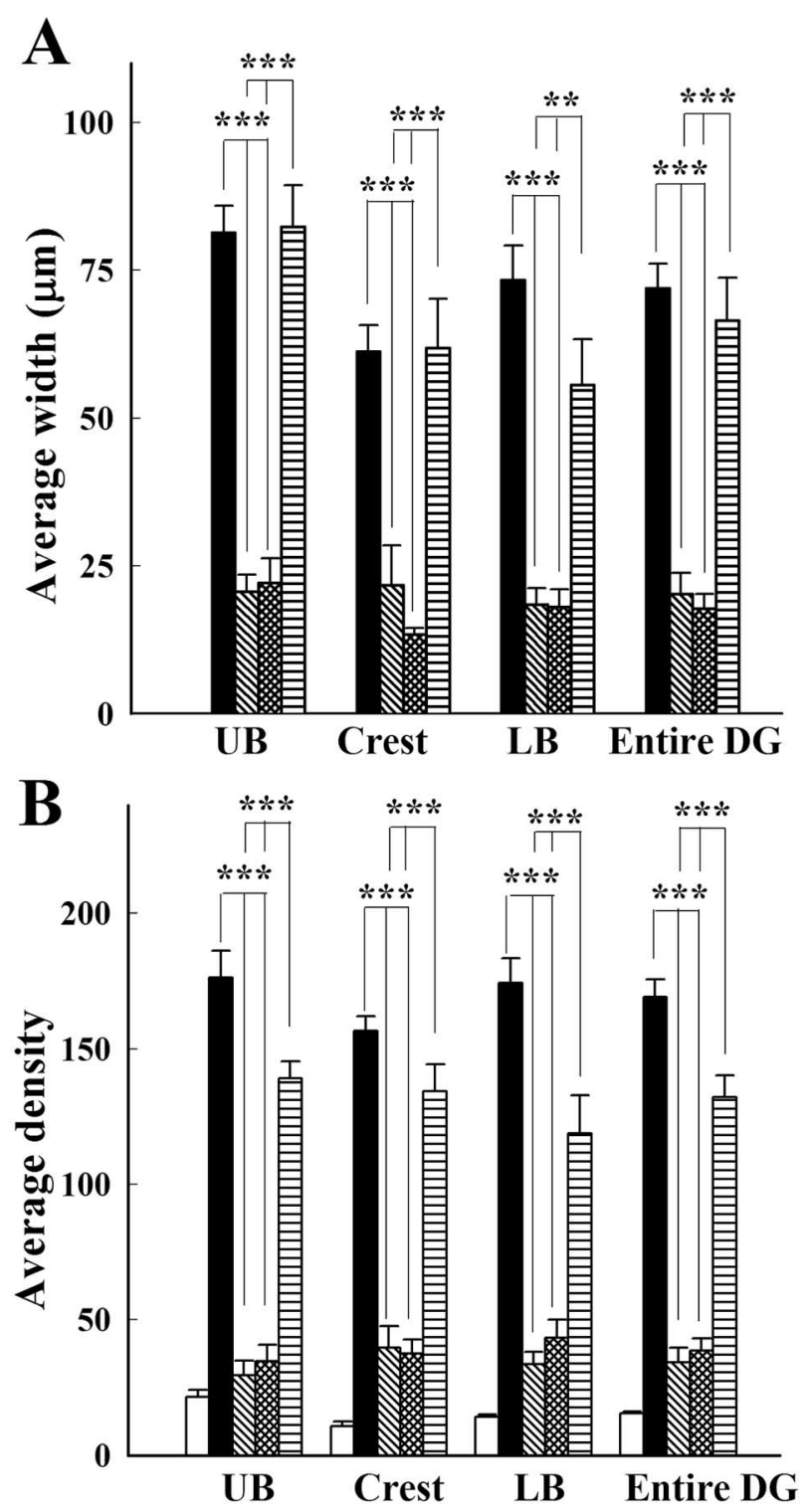

\section{$\square=$ Intact Hippocampus (Hps); $\square=$ Lesion-only Hps $\mathbb{N}=$ Hps receiving CA3 cell grafts at 4 days post-injury = Hps receiving CA3 cell grafts at 45 days post-injury 目 $=$ Hps receiving $\mathrm{CA} 1$ cell grafts}

Figure 3. Comparison of the width of sprouted area $(\boldsymbol{A})$ and the density of sprouted terminals $(\boldsymbol{B})$ in the DSGL between the intact hippocampus of control rats, the KA-lesioned hippocampus of lesion-only rats, and the KA-lesioned hippocampus of rats receiving $C A 3$ or $C A 1$ cell transplants. Note that the extent of the aberrant mossy fiber sprouting in animals receiving $C A 3$ cell grafts is dramatically less than in both lesion-only animals and animals receiving CA1 cell grafts. The CA3 graft-mediated suppression of the aberrant sprouting is consistent in all regions of the dentate gyrus. LB, Lower blade; UB, upper blade. Error bars indicate SE. ${ }^{* *} p<0.01$; ${ }^{* * *} p<0.001$.

(i.e., at $4 \mathrm{~d}$ after injury) or slightly delayed (i.e., at $45 \mathrm{~d}$ after injury) time points after the initial precipitating injury. Interestingly, in the lesioned hippocampus receiving CA1 cell transplants, both width of sprouted area and the density of sprouted terminals in all regions of the DG were comparable with that of lesion-only hippocampus and were significantly greater than the lesioned hippocampus receiving CA3 cell transplants (Fig. 3).
Thus, CA1 cell grafting has no effect on the evolution of the aberrant MFS after the initial precipitating injury.

\section{Axon growth from mouse CA3 and CA1 cell grafts transplanted into the injured rat hippocampus} We ascertained the pattern of axon growth from CA3 and CA1 cell grafts through a cross-species grafting paradigm, which comprised grafting of E15 mouse hippocampal CA3 or CA1 cells into the injured CA3 region of the adult rat hippocampus at $4 \mathrm{~d}$ after KA administration and evaluation of the graft axon growth at $30 \mathrm{~d}$ after grafting using immunostaining for a mouse-specific antigen, M6. Both CA3 and CA1 cell transplants from E15 mouse survived grafting into the injured rat hippocampus and sent axonal projections into many host sites. The overall extent and pattern of the axon growth from a CA3 cell graft placed into the injured CA3 region is illustrated in Figure $4 A 1$. Like rat CA3 cell transplants, the mouse CA3 cell grafts exhibited clusters of CA3 pyramidal-like neurons (Fig. 4B1,B2). The graft axon growth into the injured hippocampus was clearly noticeable in areas that normally receive CA3 pyramidal neuron axons. These areas also experienced deafferentation after the KA-induced destruction of the host CA3 pyramidal neurons and the dentate hilar neurons. The regions include the CA1 strata oriens and radiatum, the inner molecular layer of the DG, and the dentate hilus. In the CA1 subfield, the density of axons was robust throughout the CA1 strata oriens and radiatum (Fig. 4A2). Some axons also projected into the subiculum and the adjoining entorhinal cortex (data not shown). In the DG, the density of axons was highest in the inner molecular layer (Fig. 4A3), where the axons occupied the area of deafferentation (i.e., the DSGL). From this pattern of graft axon growth and from the overall effects of CA3 cell grafting on the aberrant MFS described previously, it appears that the CA3 cell grafts placed into the injured hippocampus induce a lasting suppression of the aberrant MFS by both innervating the deafferented DSGL and attracting a significant amount of host mossy fibers. Some graft axons also projected into the outer two-thirds of the dentate molecular layer (Fig. 4A4). Additionally, the dentate hilus exhibited a considerable amount of graft axons (Fig. $4 A 3)$.

Examination of the distant extrahippocampal regions, where the host CA3 pyramidal neurons normally project axons, demonstrated that grafted CA3 pyramidal neurons are capable of projecting axons into specific distant sites of the host brain. These include both ipsilateral and contralateral septal nuclei (hippocamposeptal pathway), and the contralateral hippocampus (commissural pathway). Comparatively, the axon growth was more vigorous into the ipsilateral septum than the contralateral septum (Fig. 4A5,A6). In the contralateral hippocampus, the axon growth was mostly restricted to the hippocampal CA3 and CA1 regions (Fig. 4A7). Efferent graft projections into the septal nuclei and the contralateral hippocampus observed here confirm our previous findings of long-distance axon growth from CA3 cell transplants using injections of retrograde axonal tracers such as the Fluoro-Gold and the DiI (Shetty et al., 2000).

Figure $5 A 1$ illustrates the pattern and the degree of axon growth from a CA1 cell transplant placed into the injured CA3 region. Despite heterotopic grafting, the CA1 cell transplants exhibited a considerable number of surviving neurons, which is consistent with our previous study (Zaman et al., 2000). The neurons were smaller (in comparison with neurons in CA3 cell grafts) and were uniformly distributed (Fig. 5B1,B2). The graft axon growth into the injured hippocampus was observed mainly in the CA1 strata oriens and radiatum and the dentate hilus (Fig. 
$5 A 2-A 4)$. The overall density of axons in CA1 strata oriens and radiatum appeared less than the density observed in these layers with CA3 cell grafting. Some axons also projected into the DG, where they distributed in all three layers (molecular layer, granule cell layer, and dentate hilus) with greater density of axons in the dentate hilus. Interestingly, in comparison with the DG of the injured hippocampus receiving CA3 cell transplants, the DG of the injured hippocampus receiving CA1 cell transplants conspicuously lacked specific and robust graft axon growth into the DSGL (Fig. 5A3,A4). The density of graft axons in the DSGL was sparse at best with some regions exhibiting complete absence of graft axons. This poor graft axon growth from CA1 cell grafts into the DSGL likely underlies the failure of CA1 cell grafts to restrain the aberrant MFS in the injured adult hippocampus. Some axon growth was also observed into the subiculum (Fig. $5 A 5$ ) and the entorhinal cortex (data not shown). Examination of the distant host sites revealed that grafted CA1 pyramidal neurons send axons to both ipsilateral and contralateral septal nuclei (Fig. 5A6) but not into the contralateral hippocampus. Even in the septum, the overall axon growth from CA1 cell transplants appeared less robust than the CA3 cell transplants. Both efferent graft projections into the septum and the lack of projections into the contralateral hippocampus observed here confirm our previous findings on distant axon growth from CA1 cell transplants using injections of retrograde axonal tracers (Shetty et al., 2000).

To validate the differences in axon growth between CA3 and CA1 cell transplants, we quantified and compared the overall graft axon growth from CA3 and CA1 cell grafts into the deafferented zones of the injured hippocampus (the CA1 strata oriens and radiatum, the dentate hilus, the dentate inner molecular layer) and the septum using M6-immunostained sections. This analysis revealed that the innervation of the deafferented zones of the injured hippocampus by graft axons is very robust with CA3 cell grafting (Fig. 6). In contrast, the axon growth from CA1 cell grafts was poor in all regions (Fig. 6). In comparison with the CA3 cell grafts, the overall axon growth from CA1 cell grafts is $43 \%$ less in the CA1 strata oriens and radiatum, $67 \%$ less in the dentate inner molecular layer, $48 \%$ less in the dentate hilus, and $44 \%$ less in the septum.

\section{Discussion}

This study provides the first evidence for the capability of fetal hippocampal CA3 cell grafts to exert a lasting suppression of the aberrant MFS into both DSGL and the CA3 stratum oriens in a rat model of TLE. A comparable suppression exerted by CA3 grafts placed at 4 or $45 \mathrm{~d}$ after injury further suggests that even a somewhat delayed grafting after injury is efficacious for suppressing aberrant MFS.
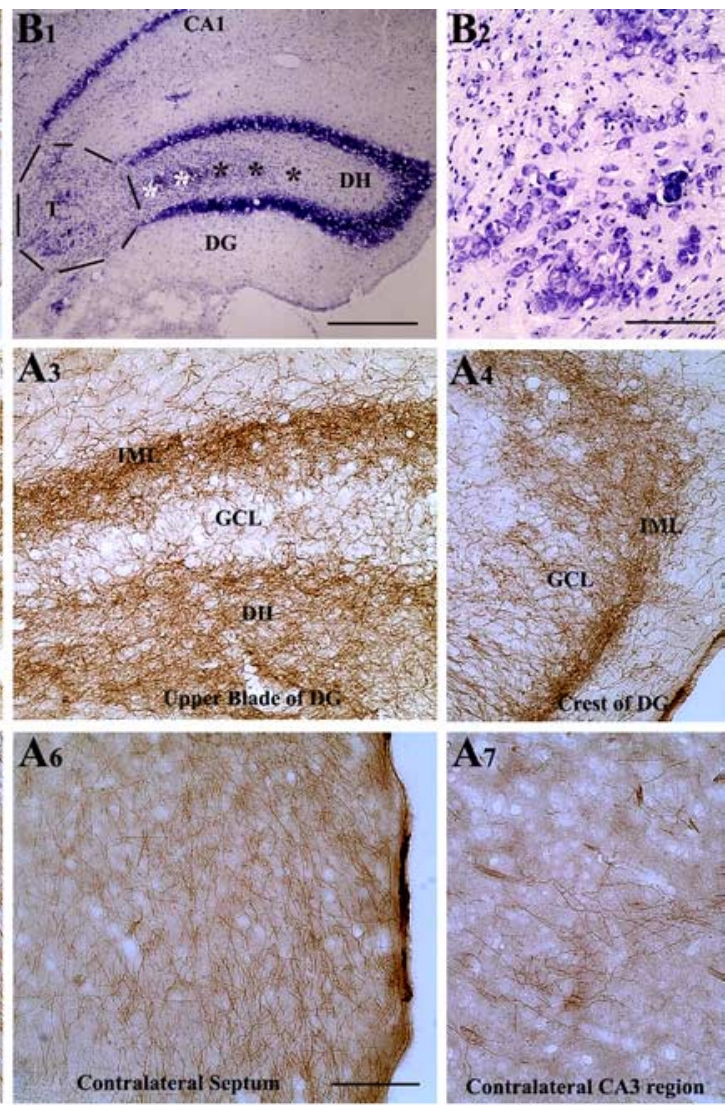

Figure 4. The pattern and extent of axon growth from a mouse CA3 cell graft into the host brain at $30 \mathrm{~d}$ after grafting, visualized A3 pyramidal neurons (indicated by asterisks) in this hippocampus. $\boldsymbol{B} 2$ is a magnified view of the transplant region showing of CA3 pyramidal neurons. The graft axon growth into the injured hippocampus is highly conspicuous in the strata orien grafts project into both ipsilateral and contralateral septal nuclei $(\boldsymbol{A 5}, \mathbf{A 6})$ and the $C A 3$ region of the contralateral hippocampus (A7). GCL, Granule cell layer; T, transplant, SP, strata pyramidale. Scale bars: A1, B1, $500 \mu \mathrm{m}$; (in A6 ) A2-A7, B2, $100 \mu \mathrm{m}$.

\section{Mechanisms of the suppression of aberrant mossy fiber sprouting by CA3 cell grafts}

A dense MFS into the DSGL after hippocampal injury is aberrant because normally mossy fibers solely project into the CA3 pyramidal and dentate hilar neurons (Amaral and Witter, 1989). The aberrant MFS occurs in two phases. The first step comprises the formation of new sprouts from the mossy fibers in the dentate hilus, which is likely triggered by injury-induced increased neural activity and upregulation of the brain-derived neurotrophic factor (Ikegaya, 1999; Binder et al., 2001; Koyama et al., 2004). The second step is the growth and extension of the mossy fiber sprouts toward the DSGL, which is possibly mediated by the following alterations in the milieu. First, the reported downregulation of the chemorepellant Sema3A in the DSGL of epileptic animals (Holtmaat et al., 2003) likely allows the sprouted terminals to invade the inner molecular layer. This is because, under normal conditions, robustly expressed chemorepellant Sema3A in the dentate molecular layer prevents mossy fibers from invading the inner molecular layer. Second, because of the KA-induced injury, granule cells lose their postsynaptic target cells and experience deafferentation in the DSGL (Sloviter, 1987). These events likely also propel the new mossy fiber sprouts to grow into the DSGL, where vacant synaptic sites are available.

With CA3 cell transplantation, host mossy fibers grow into the 

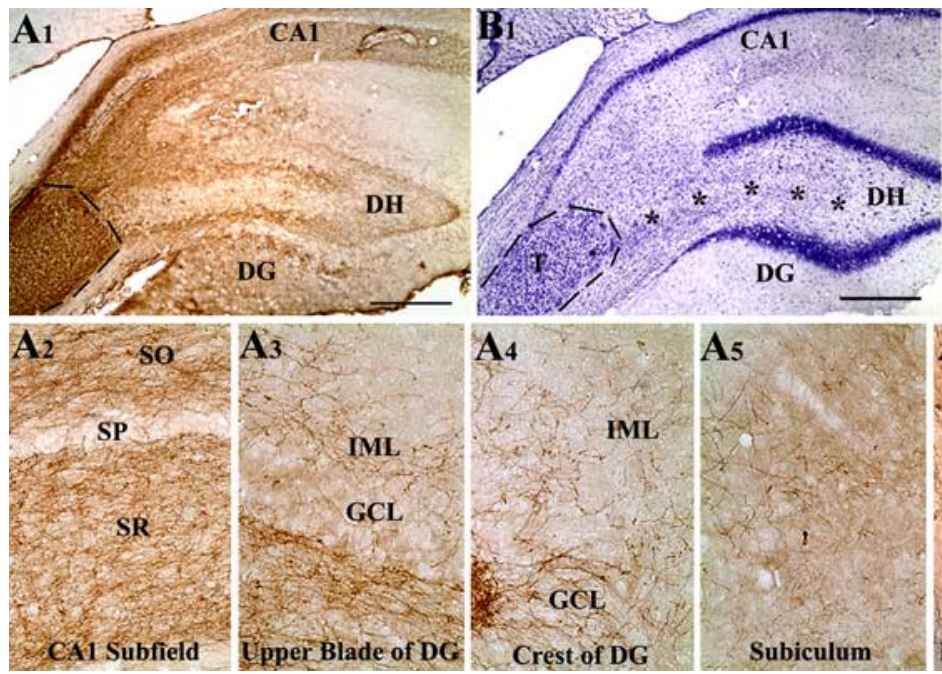

Figure 5. The pattern and degree of axon growth from a mouse CA1 cell transplant placed into the injured $C A 3$ region of the rat hippocampus (A1). B1 shows the transplant indicated in $\boldsymbol{A} \mathbf{1}$ (by interrupted lines) with Nissl staining. Note the loss of CA3 pyramidal neurons (indicated by asterisks) in the hippocampus. B2 is a magnified view of the transplant region showing the distribution of grafted CA1 cells. The graft axon growth occurs into the CA1 strata oriens (SO) and radiatum (SR) (A2); however, the extent of axon growth is considerably less than that observed with CA3 cell grafting (see Fig. 4). Note that the graft axon growth from CA1 cell graft into the inner molecular layer (IML) is conspicuously diminished $(\boldsymbol{A 3}, \boldsymbol{A 4})$ in comparison with the CA3 cell graft illustrated in Figure 4. $\boldsymbol{A} \boldsymbol{5}$ and $\boldsymbol{A} \mathbf{6}$ demonstrate axon growth from a $C A 1$ cell graft into the subiculum (A5) and the ipsilateral septal nucleus (A6). DH, Dentate hilus; $\mathrm{GCL}$, granule cell layer; T, transplant, SP, strata pyramidale. Scale bars: $\boldsymbol{A} 1, \mathbf{B 1}, 500 \mu \mathrm{m}$; (in A6) $A 2-A 6, B 2,100 \mu \mathrm{m}$.

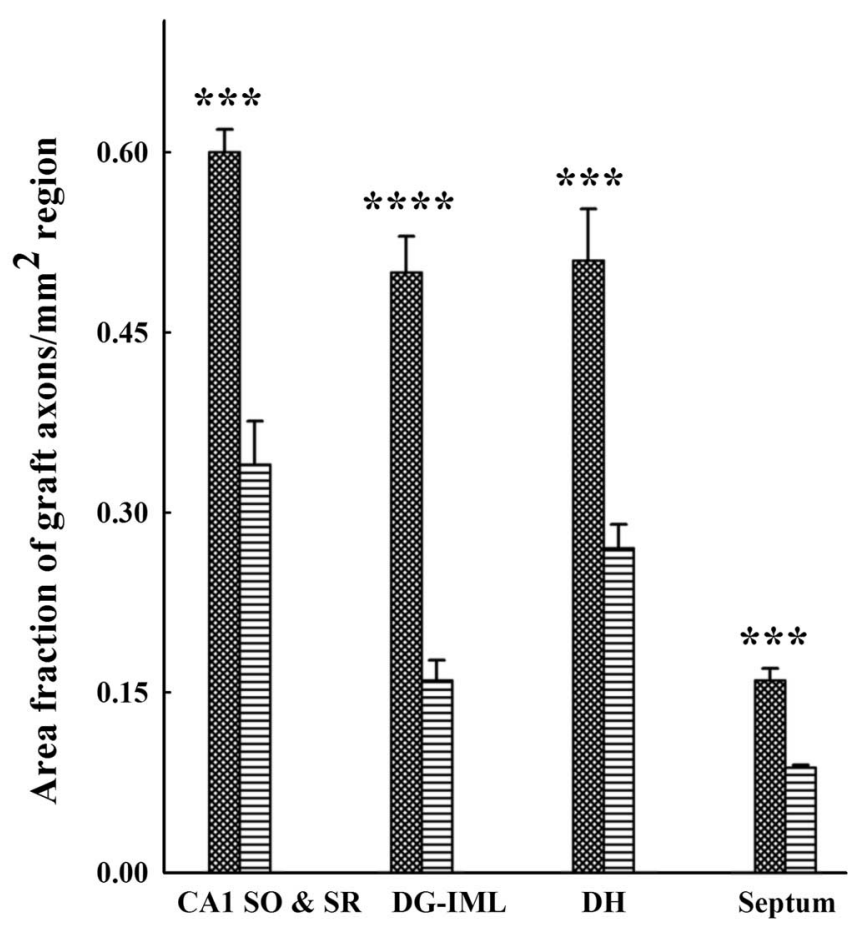

\section{网 Rats receiving $\mathrm{CA} 3$ cell grafts 目 = Rats receiving CA1 cell grafts}

Figure 6. Comparison of the overall graft axon growth from $C A 3$ and $C A 1$ cell grafts into the deafferented zones of the injured hippocampus and the septum. In comparison with the CA3 cell grafts, the overall axon growth from CA1 cell grafts is $43 \%$ less in the CA1 strata oriens and radiatum, $67 \%$ less in the dentate inner molecular layer, $48 \%$ less in the dentate hilus, and $44 \%$ less in the septum. DH, Dentate hilus; $\mathrm{SO}$, strata oriens; $\mathrm{SR}$, strata radiatum; IML, inner molecular layer. Error bars indicate SE. ${ }^{* * *} p<0.001 ;{ }^{* * * *} p<0.0001$.
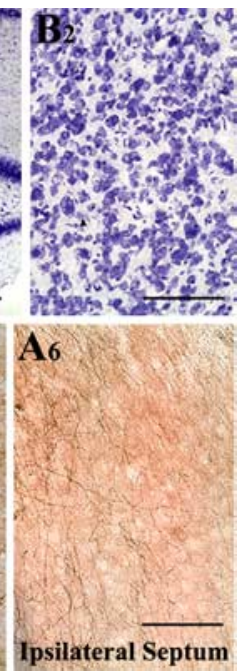

transplant where they surround the clusters of CA3 pyramidal neurons, and graft axons vigorously project into the DSGL. The CA3 transplant-mediated restitution of the disrupted circuitry is also associated with a dramatic inhibition of the aberrant MFS into both DSGL and the CA3 stratum oriens, the epileptogenic changes that ensue after the hippocampal injury. It appears that the suppression is a result of numerically dense innervation of more apt target cells (i.e., CA3 pyramidal neurons) present within the graft by host mossy fibers. Thus, when given a choice between synaptic sites in the correct postsynaptic target cells and the wrong vacant synaptic sites in granule cell dendrites, the mossy fiber sprouts in the injured hippocampus grow predominantly into the appropriate postsynaptic sites within the graft. This may be mediated by the secretion of chemoattractants specific for granule cell axons by the grafted fetal CA3 pyramidal neurons. Indeed, during development, the chemoattractants guide the growth of mossy fibers toward the CA3 region (Koyama and Ikegaya, 2004). The vigorous growth of axons from CA3 grafts into the DSGL likely also influences the mossy fiber sprouts, because the vacant synaptic sites in the DSGL are quickly occupied by graft axons. In contrast, the CA1 grafts fail to suppress the aberrant MFS in the injured hippocampus. This may be explained by the following. First, because the CA1 region during development is known to secrete factors that repel mossy fibers (Koyama and Ikegaya, 2004), it is possible that fetal CA1 grafts secrete chemorepellants that keep mossy fibers away from CA1 grafts even when placed just next to the mossy fiber bundle. Second, the CA1 grafts fail to project adequate axons into the denervated DSGL, and hence the vacant synaptic sites in the DSGL are not filled up with CA1 cell grafting, which allows the aberrant MFS into the DSGL. Thus, establishment of the reciprocal circuitry between dentate granule cells and the grafted neurons likely underlies the inhibition of the aberrant MFS by CA3 grafts.

\section{Significance of the inhibition of aberrant mossy fiber sprouting by CA 3 cell grafts for TLE}

The TLE is typified by both spontaneous recurrent motor seizures and the aberrant MFS (Houser et al., 1990; Franck et al., 1995; Engel, 1998; Gall and Lynch, 2004). However, the extent of MFS depends on the phases of TLE (Mathern et al., 1995a,b). Analyses of aberrant MFS in animal models of TLE support the concept that the dentate MFS begets granule cells to stimulate one another. First, the sprouted mossy fibers form fresh excitatory synapses on dendritic spines of granule cells (Buckmaster et al., 2002; Cavazos et al., 2003). Second, exogenous application of glutamate to the dentate molecular layer of epileptic rats induces EPSPs in granule cells that are located away from the application site (Molnar and Nadler, 1999; Lynch and Sutula, 2000). Third, antidromic stimulation of the granule cells in slices from epileptic rats evokes prolonged seizure-like bursts of population spikes in the granule cell layer, when inhibition is depressed and/or the concentration of extracellular potassium is increased (Wuarin and Dudek, 1996; Okazaki et al., 1999). Fourth, in kainate-treated 
animals with aberrant MFS, a single stimulation of the entorhinal-dentate pathway generates 3-12 successive population spikes in contrast to the single spike/stimulus observed in the saline-treated controls (Patrylo et al., 1999), suggesting that the synaptic input from the entorhinal cortex gets converted to epileptiform bursts through mossy fiber recurrent circuits (Koyama and Ikegaya, 2004). Fifth, in epileptic animals, a link has been found between the progression of MFS and the evolution of seizures (Sutula et al., 1988; Cavazos et al., 1991). Sixth, the occurrence of mutual monosynaptic interconnections between granule cells has been validated (Scharfman et al., 2003). Thus, it is clear that the aberrant MFS is associated with seizures.

However, studies also show that no correlation exists between the aberrant MFS and the first appearance of spontaneous seizures (Nissinen et al., 2001); the presence of aberrant MFS is not a prerequisite for epileptogenesis in the developing brain (Bender et al., 2003); the MFS after KA-induced injury also increases DG inhibition (Sloviter, 1992); and the new excitatory circuits after KA-induced injury develop in the CA1 region too (Shao and Dudek, 2005). Thus, it is not obvious whether the MFS is a cause or result of epilepsy. Nonetheless, because the sprouted mossy fibers make excitatory connections with the granule cell dendrites, it is credible that the aberrant MFS contributes to the chronic state of TLE (Zhang et al., 2002; Koyama and Ikegaya, 2004). Indeed, several studies suggest that the DG with aberrant MFS has increased seizure susceptibility (Mathern et al., 1996, 1998; Sutula, 2002; Nadler, 2003; Santhakumar et al., 2005). Therefore, it is reasonable to conjecture that a lasting suppression of the aberrant MFS mediated by fetal CA3 grafts likely reduces the recurrent excitation of granule cell dendrites and thereby contributes to decreased seizure susceptibility of the DG in the injured grafted hippocampus. This effect was not tested in this study, because rats treated with unilateral intracerebroventricular KA exhibit minimal and/or inconsistent spontaneous recurrent seizures. Grafting studies in animal models that exhibit significant spontaneous recurrent seizures after hippocampal injury (Hattiangady et al., 2004) are needed in the future to address this issue.

\section{Capability of CA3 cell grafts for reconstruction of the disrupted hippocampal circuitry after injury}

Previous studies suggest that transplant-mediated functional recovery after injury to discrete brain regions requires specific transplant axon growth into both local and distant host neurons leading to at least partial restitution of the damaged circuitry (Dunnett, 1995; Dunnett et al., 1997; Isacson and Deacon, 1997). Clearly, the results obtained with fetal CA3 grafting in this study satisfy these criteria for repairing the hippocampus after injury. This is because specific and vigorous axon growth occurred from CA3 grafts into the deafferented zones of both the injured hippocampus and the distant host sites. In addition, the CA3 grafts attracted considerable amounts of host mossy fibers leading to specific afferent innervation of grafted neurons. Thus, the critical requirement for functional recovery after hippocampal CA3 region injury could be accomplished via grafting of immature CA3 pyramidal cells. Conversely, the heterotopic CA1 grafts placed into the injured CA3 region fail to reconstruct the circuitry because of their inability to attract the host mossy fibers and innervate the deafferented DSGL, although they project significant amounts of axons into the CA1 subfield and the septum. Furthermore, our previous grafting studies in this hippocampal injury model have shown that only grafts containing CA3 pyramidal neurons are capable of normalizing other epileptogenic changes such as the depletions in the hippocampal GABAergic interneuron numbers (Shetty and Turner, 2000) and the loss of calbindin (Shetty, 2001). Collectively, these findings have implications for both structural and functional repair of the hippocampus after the status epilepticus, head injury, or stroke, because hippocampal injury resulting from these conditions often leads to the development of TLE (Raol et al., 2003; Rigoulot et al., 2004). Because a significant number of people afflicted with epilepsy have seizures that cannot be controlled by antiepileptic drugs (Litt et al., 2001; McKeown and McNamara, 2001), there is a need to develop alternative approaches capable of suppressing epileptogenesis after hippocampal injury. From this perspective, the grafting intervention performed after injury in this study appears promising for restraining the injury-induced epileptogenesis.

\section{References}

Amaral DA, Witter M (1989) The three-dimensional organization of the hippocampal formation: a review of anatomical data. Neuroscience 31:571-591.

Babb TL, Kupfer WR, Pretorius JK, Crandall PH, Levesque MF (1991) Synaptic reorganization by mossy fibers in human epileptic fascia dentata. Neuroscience 42:351-363.

Bender RA, Dube C, Gonzalez-Vega R, Mina EW, Baram TZ (2003) Mossy fiber plasticity and enhanced hippocampal excitability, without hippocampal cell loss or altered neurogenesis, in an animal model of prolonged febrile seizures. Hippocampus 13:399-412.

Binder DK, Croll SD, Gall CM, Scharfman HE (2001) BDNF and epilepsy: too much of a good thing? Trends Neurosci 24:47-53.

Buckmaster PS, Zhang GF, Yamawaki R (2002) Axon sprouting in a model of temporal lobe epilepsy creates a predominantly excitatory feedback circuit. J Neurosci 22:6650-6658.

Cavazos JE, Golarai G, Sutula TP (1991) Mossy fiber synaptic reorganization induced by kindling: time course of development, progression, and permanence. J Neurosci 11:2795-2803.

Cavazos JE, Zhang P, Qazi R, Sutula TP (2003) Ultrastructural features of sprouted mossy fiber synapses in kindled and kainic acid-treated rats. J Comp Neurol 458:272-292.

Danscher G (1981) Histochemical demonstration of heavy metals. A revised version of the sulphide silver method suitable for both light and electron microscopy. Histochemistry 71:1-16.

Davies SJ, Field PM, Raisman G (1994) Long interfascicular axon growth from embryonic neurons transplanted into adult myelinated tracts. J Neurosci 14:1596-1612.

Dudek FE, Obenaus A, Schweitzer JS, Wuarin JP (1994) Functional significance of hippocampal plasticity in epileptic brain: electrophysiological changes of the dentate granule cells associated with mossy fiber sprouting. Hippocampus 4:259-265.

Dunnett SB (1995) Functional repair of striatal systems by neural transplants: evidence for circuit reconstruction. Behav Brain Res 66:133-142.

Dunnett SB, Kendall AL, Watts C, Torres EM (1997) Neuronal cell transplantation for Parkinson's and Huntington's diseases. $\mathrm{Br}$ Med Bull 53:757-776.

Engel Jr J (1998) Classifications of the International League Against Epilepsy: time for reappraisal. Epilepsia 39:1014-1017.

Franck JE, Pokorny J, Kunkel DD, Schwartzkroin PA (1995) Physiologic and morphologic characteristics of granule cell circuitry in human epileptic hippocampus. Epilepsia 36:543-558.

Gall CM, Lynch G (2004) Integrins, synaptic plasticity and epileptogenesis. Adv Exp Med Biol 548:12-33.

Hattiangady B, Rao MS, Shetty AK (2004) Chronic temporal lobe epilepsy is associated with severely declined dentate neurogenesis in the adult hippocampus. Neurobiol Dis 17:473-490.

Holtmaat AJ, Gorter JA, De Wit J, Tolner EA, Spijker S, Giger RJ, Lopes da Silva FH, Verhaagen J (2003) Transient downregulation of Sema3A mRNA in a rat model for temporal lobe epilepsy. A novel molecular event potentially contributing to mossy fiber sprouting. Exp Neurol 182:142-150.

Houser CR, Miyashiro JE, Swartz BE, Walsh GO, Rich JR, Daelgado-Escuet AV (1990) Altered patterns of dynorphin immunoreactivity suggest 
mossy fiber reorganization in human hippocampal epilepsy. J Neurosci $10: 267-282$.

Ikegaya Y (1999) Abnormal targeting of developing hippocampal mossy fibers after epileptiform activities via L-type $\mathrm{Ca}^{2+}$ channel activation in vitro. J Neurosci 19:802-812.

Isacson O, Deacon T (1997) Neural transplantation studies reveal the brain's capacity for continuous reconstruction. Trends Neurosci 20:477-482.

Koyama R, Ikegaya Y (2004) Mossy fiber sprouting as a potential therapeutic target for epilepsy. Curr Neurovasc Res 1:3-10.

Koyama R, Yamada MK, Nishiyama N, Matsuki N, Ikegaya Y (2004) Developmental switch in axon guidance modes of hippocampal mossy fibers in vitro. Dev Biol 267:29-42.

Litt B, Esteller R, Echauz J, D’Alessandro M, Shor R, Henry T, Pennell P, Epstein C, Bakay R, Dichter M, Vachtsevanos G (2001) Epileptic seizures may begin hours in advance of clinical onset: a report of five patients. Neuron 30:51-64.

Lynch M, Sutula T (2000) Recurrent excitatory connectivity in the dentate gyrus of kindled and kainic acid-treated rats. J Neurophysiol 83:693-704.

Mathern GW, Cifuentes F, Leite JP, Pretorius JK, Babb TL (1993) Hippocampal EEG excitability and chronic spontaneous seizures are associated with aberrant synaptic reorganization in the rat intrahippocampal kainate model. Electroencephalogr Clin Neurophysiol 87:326-339.

Mathern GW, Pretorius JK, Babb TL (1995a) Influence of the type of initial precipitating injury and at what age it occurs on course and outcome in patients with temporal lobe seizures. J Neurosurg 82:220-227.

Mathern GW, Pretorius JK, Babb TL, Quinn B (1995b) Unilateral hippocampal mossy fiber sprouting and bilateral asymmetric neuron loss with episodic postictal psychosis. J Neurosurg 82:228-233.

Mathern GW, Babb TL, Leite JP, Pretorius K, Yeoman KM, Kuhlman PA (1996) The pathogenic and progressive features of chronic human hippocampal epilepsy. Epilepsy Res 26:151-161.

Mathern GW, Price G, Rosales C, Pretorius JK, Lozada A, Mendoza D (1998) Anoxia during kainate status epilepticus shortens behavioral convulsions but generates hippocampal neuron loss and supragranular mossy fiber sprouting. Epilepsy Res 30:133-151.

McKeown MJ, McNamara JO (2001) When do epileptic seizures really begin? Neuron 30:1-3.

Mitchell J, Sundstrom LE, Wheal HV (1993) Microglial and astrocytic cell responses in the rat hippocampus after an intracerebroventricular kainic acid injection. Exp Neurol 121:224-230.

Molnar P, Nadler JV (1999) Mossy fiber-granule cell synapses in the normal and epileptic rat dentate gyrus studied with minimal laser photostimulation. J Neurophysiol 82:1883-1894.

Nadler JV (2003) The recurrent mossy fiber pathway of the epileptic brain. Neurochem Res 28:1649-1658.

Nissinen J, Lukasiuk K, Pitkanen A (2001) Is mossy fiber sprouting present at the time of the first spontaneous seizures in rat experimental temporal lobe epilepsy? Hippocampus 11:299-310.

Okazaki MM, Molnar P, Nadler JV (1999) Recurrent mossy fiber pathway in rat dentate gyrus: synaptic currents evoked in presence and absence of seizure-induced growth. J Neurophysiol 81:1645-1660.

Patrylo PR, Schweitzer JS, Dudek FE (1999) Abnormal responses to perforant path stimulation in the dentate gyrus of slices from rats with kainate-induced epilepsy and mossy fiber reorganization. Epilepsy Res 36:31-42.

Paxinos G, Watson C (1998) The rat brain in stereotaxic coordinates. New York: Academic.

Raol YS, Budreck EC, Brooks-Kayal AR (2003) Epilepsy after early-life seizures can be independent of hippocampal injury. Ann Neurol 53:503-511.

Represa A, Ben-Ari Y (1992) Kindling is associated with the formation of novel mossy fiber synapses in the CA3 region. Exp Brain Res 92:69-78.

Represa A, Jorquera I, Le Gall La Salle G, Ben-Ari Y (1993) Epilepsy induced collateral sprouting of hippocampus mossy fibers: does it induce the development of ectopic synapses with granule cell dendrites? Hippocampus 3:257-268.

Rigoulot MA, Koning E, Ferrandon A, Nehlig A (2004) Neuroprotective properties of topiramate in the lithium-pilocarpine model of epilepsy. J Pharmacol Exp Ther 308:787-795.
Santhakumar V, Aradi I, Soltesz I (2005) Role of mossy fiber sprouting and mossy cell loss in hyperexcitability: a network model of the dentate gyrus incorporating cell types and axonal topography. J Neurophysiol 93:437-453.

Scharfman HE, Sollas AL, Berger RE, Goodman JH (2003) Electrophysiological evidence of monosynaptic excitatory transmission between granule cells after seizure-induced mossy fiber sprouting. J Neurophysiol 90:2536-2547.

Shao LR, Dudek FE (2005) Detection of increased local excitatory circuits in the hippocampus during epileptogenesis using focal flash photolysis of caged glutamate. Epilepsia 46 [Suppl 5]:100-106.

Shetty AK (2001) Fetal hippocampal CA3 cell grafts into the lesioned adult CA3 restore host hippocampal calbindin in a rat model of temporal lobe epilepsy. Soc Neurosci Abstr 27:371.10.

Shetty AK, Turner DA (1995a) Enhanced cell survival in fetal hippocampal suspension transplants grafted to adult rat hippocampus following kainate lesions: a three-dimensional graft reconstruction study. Neuroscience 67:561-582.

Shetty AK, Turner DA (1995b) Intracerebroventricular kainic acid administration in adult rat alters hippocampal calbindin and nonphosphorylated neurofilament expression. J Comp Neurol 363:581-599.

Shetty AK, Turner DA (1996) Development of fetal hippocampal grafts in intact and lesioned hippocampus. Prog Neurobiol 50:597-653.

Shetty AK, Turner DA (1997) Fetal hippocampal cells grafted to kainatelesioned CA3 of adult hippocampus suppress aberrant supragranular sprouting of mossy fibers. Exp Neurol 143:231-245.

Shetty AK, Turner DA (1999) Aging impairs axonal sprouting response of dentate granule cells following target loss and partial deafferentation. J Comp Neurol 414:238-254.

Shetty AK, Turner DA (2000) Fetal hippocampal grafts containing CA3 cells restore host hippocampal glutamate decarboxylase-positive interneuron numbers in a rat model of temporal lobe epilepsy. J Neurosci 20:8788-8801.

Shetty AK, Zaman V, Turner DA (2000) Pattern of long-distance projections from fetal hippocampal field CA3 and CA1 cell grafts in lesioned CA3 of adult hippocampus follows intrinsic character of respective donor cells. Neuroscience 99:243-255.

Shetty AK, Zaman V, Shetty GA (2003) Hippocampal neurotrophin levels in a kainate model of temporal lobe epilepsy: a lack of correlation between brain-derived neurotrophic factor content and progression of aberrant dentate mossy fiber sprouting. J Neurochem 87:147-159.

Sloviter RS (1987) Decreased hippocampal inhibition and selective loss of interneurons in experimental epilepsy. Science 235:73-76.

Sloviter RS (1992) Possible functional consequences of synaptic reorganization in the dentate gyrus of kainate-treated rats. Neurosci Lett 137:91-96.

Sutula T (2002) Seizure-induced axonal sprouting: assessing connections between injury, local circuits, and epileptogenesis. Epilepsy Curr 2:86-91.

Sutula T, Xiao-Xian H, Cavazos J, Scott G (1988) Synaptic reorganization in the hippocampus induced by abnormal functional activity. Science 239:1147-1150.

Turner DA, Shetty AK (2003) Clinical prospects for neural grafting therapy for hippocampal lesions and epilepsy. Neurosurgery 52:632-644.

Wuarin JP, Dudek FE (1996) Electrographic seizures and new recurrent excitatory circuits in the dentate gyrus of hippocampal slice from kainate treated epileptic rats. J Neurosci 16:4438-4448.

Wuarin JP, Dudek FE (2001) Excitatory synaptic input to granule cells increases with time after kainate treatment. J Neurophysiol 185:1067-1077.

Zaman V, Shetty AK (2001) Fetal hippocampal CA3 cell grafts transplanted to lesioned CA3 region of the adult hippocampus exhibit long-term survival in a rat model of temporal lobe epilepsy. Neurobiol Dis 8:942-952.

Zaman V, Turner DA, Shetty AK (2000) Survival of grafted fetal neural cells in kainic acid lesioned CA3 region of adult hippocampus depends upon cell specificity. Exp Neurol 161:535-561.

Zaman V, Turner DA, Shetty AK (2001) Prolonged post lesion transplantation delay adversely influences survival of both homotopic and heterotopic fetal hippocampal cell grafts in kainate-lesioned CA3 region of adult hippocampus. Cell Transplant 10:41-52.

Zhang X, Cui SS, Wallace AE, Hannesson DK, Schmued LC, Saucier DM, Honer WG, Corcoran ME (2002) Relations between brain pathology and temporal lobe epilepsy. J Neurosci 22:6052-6061. 